\title{
Laminin functionalized biomimetic apatite to regulate the adhesion and proliferation behaviors of neural stem cells
}

This article was published in the following Dove Press journal: International Journal of Nanomedicine

\author{
Dandan Luo' \\ Shichao Ruan' \\ Aiping Liu ${ }^{2}$ \\ Xiangdong Kong ${ }^{3}$ \\ In-Seop Lee Le $^{3,4}$ \\ Cen Chen ${ }^{1,5}$ \\ 'College of Life Sciences, Zhejiang \\ Sci-Tech University, Hangzhou 310018 , \\ People's Republic of China; ${ }^{2}$ Center \\ for Optoelectronics Materials and \\ Devices, Zhejiang Sci-Tech University, \\ Hangzhou 310018 , People's Republic \\ of China; ${ }^{3}$ College of Materials and \\ Textiles, Zhejiang Sci-Tech University, \\ Hangzhou 310018 , People's Republic \\ of China; ${ }^{4}$ nstitute of Natural \\ Sciences, Yonsei University, Seoul \\ 03722, Korea; ${ }^{5}$ Zhejiang Provincial Key \\ Laboratory of Silkworm Bioreactor \\ and Biomedicine, Hangzhou 310018 , \\ People's Republic of China
}

Correspondence: Cen Chen College of Life Sciences, Zhejiang Sci-Tech University, No 928, 2nd Street, Xiasha High Education Area, Hangzhou 310018, People's Republic of China Tel $+8657 \mid 86843555$

Fax +86 57। 86843303

Email chencen313@gmail.com

In-Seop Lee Institute of Natural Sciences, Yonsei University, I 34 Shinchon-dong, Seodaemoon-gu, Seoul 03722, Korea Tel +82221234806

Fax +82 23133537

Email inseop@yonsei.ac.kr
Background: Functionalizing biomaterial substrates with biological signals shows promise in regulating neural stem cell (NSC) behaviors through mimicking cellular microenvironment. However, diverse methods for immobilizing biological molecules yields promising results but with many problems. Biomimetic apatite is an excellent carrier due to its non-toxicity, good biocompatibility, biodegradability, and favorable affinity to plenty of molecules. Therefore, it may provide a promising alternative in regulating NSC behaviors.

Methods: Biomimetic apatite immobilized with the extracellular protein-laminin(LN) was prepared through coprecipitation process in modified Dulbecco's phosphate-buffered saline (DPBS) containing LN. The amount of coprecipitated LN and their release kinetics were examined. The adhesion and proliferation behaviors of NSC on biomimetic apatite immobilized with LN were investigated.

Results: The coprecipitation approach provided well retention of LN within biomimetic apatite up to 28 days, and supported the adhesion and proliferation of NSCs without cytotoxicity. For long-term cultivation, NSCs formed neurosphere-like aggregates on non-functionalized biomimetic apatite. A monolayer of proliferated NSCs on biomimetic apatite with coprecipitated LN was observed and even more stable than the positive control of LN coated tissue-culture treated polystyrene (TCP).

Conclusion: The simple and reproducible method of coprecipitation suggests that biomimetic apatite is an ideal carrier to functionalize materials with biological molecules for neural-related applications.

Keywords: biomimetic apatite, neural stem cell, coprecipitation, adhesion, proliferation, laminin

\section{Introduction}

Neural stem cells (NSCs), which can be obtained from either embryonic or adult central nervous system, ${ }^{1}$ possess self-renewal ability and the potential to differentiate into all three neural lineages - neurons, astrocytes, and oligodendrocytes. ${ }^{2}$ Therefore, NSCs are regarded as a potential source for the treatment of neurological dysfunctions such as Parkinson's disease, ${ }^{3}$ Alzheimer's disease, ${ }^{4}$ and stroke. ${ }^{5}$ However, the lack of efficient procedures to regulate the proliferation and differentiation behaviors of NSCs limits the NSC survival or cell fate controlling in vivo. ${ }^{6}$ Strategies to guide cell behaviors by recreating a biomimetic environment for NSCs have been developed. This requires functionalizing biomaterial substrates to provide physicochemical cues and/or biological signals.

Immobilizing biological molecules onto biomaterial substrates could be an efficient strategy for rendering biological signals, which results in manipulating NSC behaviors. ${ }^{7}$ Biological molecules of interest include large extracellular matrix (ECM) proteins such as laminin $(\mathrm{LN})$ that engage several integrin receptors of cell surfaces ${ }^{8}$ or growth factors, 
which control NSC proliferation and differentiation. ${ }^{9}$ Diverse methods such as physical adsorption and covalent chemical bonding have been applied to immobilize biological molecules on the surfaces of substrates. ${ }^{10-13}$ However, immobilizing biological molecules through physical adsorption yields unsatisfying results such as low surface adsorption efficiency and initial rapid diffusion. ${ }^{14}$ Typical chemical approach requires tedious cross-linking procedures with organic chemical solution, which may destruct the surface feature of substrates and denature immobilized molecules. ${ }^{15}$ Therefore, it is crucial to develop a simple and effective immobilization strategy.

Biomimetic apatite, a naturally occurring inorganic material, is currently widely used for biomedical applications ${ }^{16}$ due to its non-toxicity, ${ }^{17}$ excellent biocompatibility, ${ }^{18}$ biodegradability, ${ }^{19}$ and favorable affinity to plenty of molecules. ${ }^{20,21}$ Biomimetic apatite can be easily formed on various substrates, such as metallic materials, ${ }^{22}$ polymeric materials, ${ }^{23}$ and natural materials, ${ }^{24}$ through biomimetic precipitation in a moderate condition. One of the important advantages of this biomimetic apatite is easy to control the dosage of biological molecules by simultaneous coprecipitation with apatite. ${ }^{25}$ Multiple molecules could be coprecipitated into biomimetic apatite with controlled spatial localization, which could manipulate the release kinetics of biological molecules to regulate attached cell behaviors. ${ }^{26}$

Our previous studies have reported that adhesion, proliferation, and osteogenic differentiation of mesenchymal stem cells were enhanced by dual loading of osteogenic growth peptide and fibronectin within biomimetic apatite, ${ }^{27}$ and the proliferation of smooth muscle cell was inhibited by apatite/sirolimus composite layer. ${ }^{28}$ Yamaguch et $\mathrm{al}^{29}$ also demonstrated that biomimetic apatite formed on chitosan tube improved the nerve regeneration due to increased mechanical properties of chitosan tube by inner apatite coating. Now it is worth to investigate whether biomimetic apatite could serve as a carrier to affect NSC behaviors.

$\mathrm{LN}$, one of the ECM components, which is continuously synthesized after nerve injury ${ }^{30}$ and plays an important role in facilitating cell adhesion, proliferation, and neurite outgrowth, ${ }^{31}$ was chosen in this study. Different amounts of LN were coprecipitated with biomimetic apatite (apatite/LN). Physiochemical characterizations of apatite/LN were analyzed by scanning electron microscopy (SEM) and X-ray photoelectron spectroscopy (XPS). The release kinetics and retention of coprecipitated LN were examined using fluorescent spectrophotometer and observed by confocal microscope. The effects of LN amount on NSC adhesion were evaluated. The cell morphology, proliferation, and cytotoxicity were also investigated.

\section{Materials and methods Materials}

Dulbecco's phosphate-buffered saline (DPBS, without calcium and magnesium), phosphate-buffered saline (PBS), accutase cell dissociation reagent, micro BCA protein assay kit (mBCA), serum albumin and live/dead viability/cytotoxicity kit were purchased from Thermo Fisher Scientific (Waltham, MA, USA). $\mathrm{LN}$ from murine, $\mathrm{CaCl}_{2}$ solution, $\mathrm{NaOH}$ beads, acetone, absolute ethanol, and glutaraldehyde were obtained from Sigma-Aldrich (St Louis, MO, USA). Fluorescein isothiocyanate-conjugated LN (FITC-LN) was synthesized by Solarbio (Beijing, People's Republic of China). NSC derived from brain tissues of Sprague Dawley (SD) rat embryos and NSC growth medium were obtained from Cyagen Biosciences (Soochow, People's Republic of China). Mouse monoclonal anti-nestin was purchased from Abcam (Cambridge, UK). Secondary antibodies for immunofluorescence staining, Triton $\mathrm{X}-100$, nuclei visualization solution DAPI, and Cell Counting Kit-8 (CCK8) were obtained from Beyotime Biotechnology (Shanghai, People's Republic of China). All cell culture flask and multi-well plates were purchased from Corning Incorporated (Corning, NY, USA).

\section{Preparation of biomimetic apatite and apatite/LN}

As shown in Figure 1, titanium substrates coated with biomimetic apatite or apatite/LN were prepared by alkali treatment

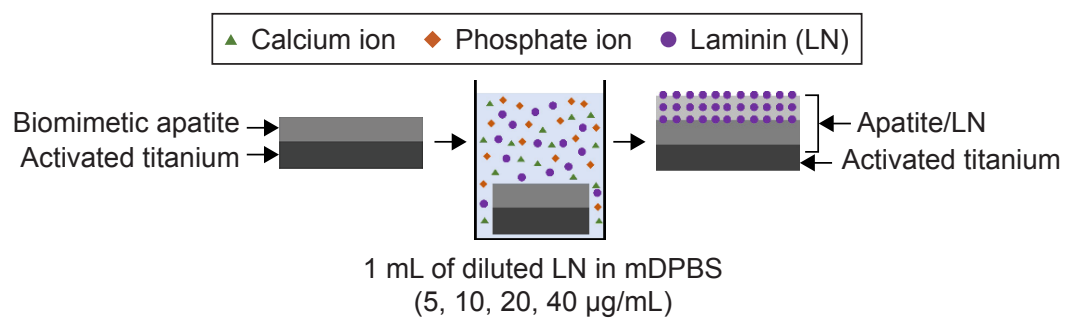

Figure I Schematic illustration of coprecipitating LN within biomimetic apatite. Abbreviations: LN, laminin; mDPBS, modified Dulbecco's phosphate-buffered saline. 
and biomimetic precipitation, ${ }^{27}$ as described previously. $\mathrm{CaCl}_{2}$ solution $(100 \mathrm{mg} / \mathrm{L})$ was added to DPBS to prepare the modified DPBS (mDPBS) solution. Stock LN solution $(1 \mathrm{mg} / \mathrm{mL})$ was diluted to $5,10,20$, and $40 \mu \mathrm{g} / \mathrm{mL}$ in mDBPS, and these diluted solutions were denoted as LN5, LN10, LN20, and LN40, respectively. The titanium substrates were first activated as below. Commercially pure titanium discs (grade IV, $10 \mathrm{~mm}$ in diameter, $2 \mathrm{~mm}$ in thickness) were ultrasonically washed in acetone, absolute ethanol, and distilled water for 15 minutes each and then soaked in $5 \mathrm{~mL}$ of $1 \mathrm{M}$ $\mathrm{NaOH}$ solution at $140^{\circ} \mathrm{C}$ for 6 hours. For biomimetic apatite precipitation, the activated titanium was immersed in $5 \mathrm{~mL}$ of mDPBS at $37^{\circ} \mathrm{C}$ for 24 hours. For further coprecipitation of $\mathrm{LN}$, the biomimetic apatite-coated titanium was immersed in $1 \mathrm{~mL}$ of diluted $\mathrm{LN}$ solution at $25^{\circ} \mathrm{C}$ for another 24 hours. The surface morphologies were taken from random fields of biomimetic apatite, apatite/LN5, apatite/LN10, apatite/LN20, and apatite/LN40 by SEM (Quanta 200; FEI Company, Philips, the Netherlands). The sizes of 15 independent flakes for each group were measured with ImageJ software.

\section{Amount of coprecipitated LN}

The amount of coprecipitated LN was quantified by subtracting the amount of residual $\mathrm{LN}$ from that of the initially added LN using mBCA assay. Absorbance was measured at $562 \mathrm{~nm}$ using an ultraviolet/visible spectrophotometer (Shimadzu, Kyoto, Japan) and then was converted to LN concentration using an albumin standard curve. The surfaces of biomimetic apatite and apatite/LN were then evaluated by XPS (PHI-5300 ESCA, Physical Electronics, Inc., Chanhassen, MN, USA) to study the chemical composition. The data were acquired by using $\mathrm{A} 1 \mathrm{~K} \alpha \mathrm{X}$-rays with the photoelectron take-off angle being set at $45^{\circ}$.

\section{In vitro release of coprecipitated $L N$}

To quantify the release kinetics of coprecipitated LN from biomimetic apatite, we chose FITC-LN as the FITC tag allowed LN amount to be measured through fluorescent spectrophotometry. The FITC-LN $(20 \mu \mathrm{g} / \mathrm{mL})$ was coprecipitated as previously stated in the "Preparation of biomimetic apatite and apatite/LN" section. Titanium substrates coated with apatite/FITC-LN were incubated in $1 \mathrm{~mL}$ of PBS at $37^{\circ} \mathrm{C}$ for 28 days under gentle orbital shaking (HNY-100D, Tianjin Honor Instrument Co., Ltd, People's Republic of China). At specific time points, the supernatant was completely collected and fresh PBS was replenished. The amount of released FITC-LN was measured at Ex/Em $495 / 519 \mathrm{~nm}$ by microplate reader (VL0000D0; Thermo Fisher Scientific).
The retention of coprecipitated FITC-LN within apatite after 28 days was imaged using confocal microscope (MRC1024MP, Bio-Rad Laboratories Inc., Hercules, CA, USA) under excitation wavelength of $488 \mathrm{~nm}$. For the control, sample was kept in air, and another sample was incubated in PBS solution for retention test. Using the Bio-Rad Radiance 2000 LaserSharp imaging program, a series of images was taken in 1- $\mu \mathrm{m}$ interval and the cross-section profile through the thickness of apatite/FITC-LN20 was obtained by stacking the series of images.

\section{Cultivation of NSCs}

NSCs were propagated as described ${ }^{32}$ with the neurosphere method. Single cells were suspended in growth medium containing basal medium, B27, penicillin-streptomycin, glutamine, epidermal growth factor (EGF, $20 \mathrm{ng} / \mathrm{mL}$ ), basic fibroblast growth factor (bFGF; $20 \mathrm{ng} / \mathrm{mL}$ ), and heparin $(5 \mu \mathrm{g} / \mathrm{mL})$ and then plated at a density of $2.0 \times 10^{5}$ cells $/ \mathrm{mL}$ into a tissue culture flask. Cells were incubated in $37^{\circ} \mathrm{C}$, humidified, 5\% $\mathrm{CO}_{2}$ environment. Every 3-5 days, floating cell aggregates were collected and dissociated into single cells by treatment with accutase and subcultured to form the secondary aggregates. Cells of passage 3-7 were used for further cell experiments.

\section{NSC adhesion and proliferation}

Each biomimetic apatite-coated titanium disc was sterilized in $75 \%$ ethanol, washed with distilled water, and placed under ultraviolet light overnight. Experimental samples were prepared as mentioned in the "Preparation of biomimetic apatite and apatite/LN" section using sterilized solutions. Cells were seeded on samples at a cell density of $1 \times 10^{5}$ cells $/ \mathrm{mL}$. LN $(20 \mu \mathrm{g} / \mathrm{mL})$ coated tissue culture-treated polystyrene (TCP) surfaces were used as a positive control (Ctr+), and non-coated surfaces were used as a negative control (Ctr-). For adhesion assay, initial cell adhesion was measured for 12-hour cultivation. After gently washing samples with PBS three times to remove non-adhered cells, the attached cells were measured by CCK8. Long-term proliferation was investigated by allowing cells to grow on samples for 3, 5, 7, and 10 days, with changing medium every 3 days. At predetermined time point, samples were assessed by CCK8 and observed by immunofluorescence staining.

\section{Indirect cytotoxicity}

Cytotoxicity was assessed using CCK8 and the live/dead viability/cytotoxicity kit, where NSCs were exposed to the extract mediums of biomimetic apatite and apatite/LN20 for 48 hours. To prepare the extract mediums for indirect 
cytotoxicity, NSC growth medium was incubated with biomimetic apatite or apatite/LN20 samples for 72 hours at $37^{\circ} \mathrm{C}$. NSC growth medium was used as a negative control (Ctr-) and NSC growth medium with $0.64 \%$ phenol was used as a positive control (Ctr+). For the quantitative assay, NSCs viability was evaluated by CCK 8 as described above. For the qualitative assay, cytotoxicity was analyzed using the live/ dead viability/cytotoxicity kit, according to the manufacture's protocol. ${ }^{33}$ Briefly, at the end of 48-hour exposure, cells were washed with PBS followed by the addition of $2 \mu \mathrm{M}$ Calcein AM and $4 \mu \mathrm{M}$ ethidium homodimer (EthD-1). After incubation for 30 minutes at $37^{\circ} \mathrm{C}$, the cells were observed under a confocal microscope (IX81-FV1000, Olympus Corporation, Tokyo, Japan), with excitation and emission of green (Ex/Em 494/530 nm for Calcein AM) and red (Ex/Em 528/645 nm for EthD-1) fluorescence.

\section{Immunofluorescence staining}

For immunofluorescence staining, cells were fixed with $2.5 \%$ glutaraldehyde for 30 minutes and permeabilized with $0.1 \%$ (v/v) Triton X-100 (in PBS) for 30 minutes. The cells were then blocked with $2 \%(\mathrm{v} / \mathrm{v})$ serum albumin for 1 hour and incubated with primary antibodies overnight at $4^{\circ} \mathrm{C}$. Cells grown in proliferative conditions were stained using mouse anti-nestin (1:200). Detection of primary antibodies was performed with FITC-conjugated goat anti-mouse antibodies at a 1:500 dilution for 1 hour. Cell nuclei were counterstained with DAPI. Immunofluorescence staining was observed under a confocal microscope.

\section{Statistical analysis}

All quantitative data were obtained from two or more independent experiments with triplicate or quadrant repeats and expressed as the mean $\mathrm{SD}$. Tests of significance were performed using Student's $t$-test. The difference was considered statistically significant for a value of $* P<0.05$ and $* * P<0.01$.

\section{Results SEM examination}

The surface morphologies of biomimetic apatite, apatite/LN5, apatite/LN10, apatite/LN20, and apatite/LN40 revealed by SEM (Figure 2) were consistent with previous studies. ${ }^{27}$ Both biomimetic apatite and apatite/LN displayed homogeneous porous structure composed of straight, flake-like, sharpedged units. The flake sizes of apatite/LN5 (8.65 $\pm 0.90 \mu \mathrm{m}$ in Figure 2B), apatite/LN10 (9.44 $\pm 0.99 \mu \mathrm{m}$ in Figure 2C), apatite/LN20 (9.79 $\pm 0.69 \mu \mathrm{m}$ in Figure 2D), and apatite/LN40 $(9.31 \pm 0.88 \mu \mathrm{m}$ in Figure 2E) were slightly larger than that of biomimetic apatite only $(8.16 \pm 0.87 \mu \mathrm{m}$ in Figure $2 \mathrm{~A})$.

\section{Quantification and release kinetics of coprecipitated LN}

From the mBCA assay, the concentration of LN in mDPBS solution decreased after immersing biomimetic apatite-coated titanium for 24 hours. Table 1 shows the amount of coprecipitated LN on each sample with different initial concentration of LN. The amount of coprecipitated LN increased from approximately $1.43 \mu \mathrm{g}$ to nearly $5.88 \mu \mathrm{g}$, with increasing initial concentration of LN from 5 to $40 \mu \mathrm{g} / \mathrm{mL}$.

The XPS spectra revealed the change in surface chemical compositions caused by coprecipitation of biological molecules (Figure 3A). The surface of biomimetic apatite presented typical photoelectron peaks, Ca $2 \mathrm{p}(346.88 \mathrm{eV})$, P 2p (132.88 eV), O 1s (530.78 eV), and C 1s (284.88 eV). The $\mathrm{N}$ 1s peaks $(399.78 \mathrm{eV})$ originated from nitrogen components of LN were newly detected in the XPS spectrum from apatite with coprecipitated LN (apatite/LN5, apatite/LN10, apatite/LN20, and apatite/LN40). The magnified XPS spectrum of $\mathrm{N}$ peaks displayed that nitrogen intensity increased with increasing initial LN concentration in mDPBS solution. As shown in Figure 3B, XPS quantitative analysis demonstrated that the contents of nitrogen and carbon increased owing to the presence of LN, while contents of calcium and phosphorus from the underlying layer decreased. All the
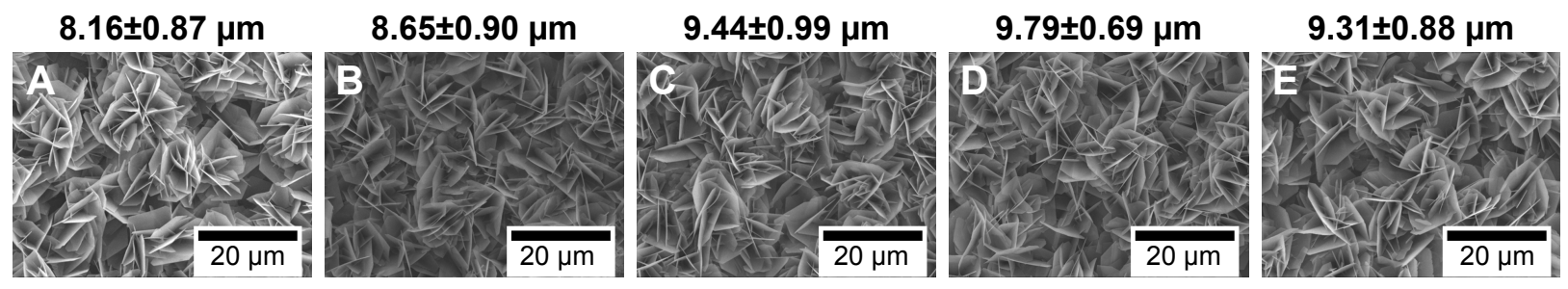

Figure 2 SEM images of surfaces morphologies of (A) biomimetic apatite, (B) apatite/LN5, (C) apatite/LNI0, (D) apatite/LN20, and (E) apatite/LN40. Scale bar is 20 $\mu \mathrm{m}$ in length.

Abbreviations: LN, laminin; SEM, scanning electron microscope. 
Table I Amount of LN coprecipitated within biomimetic apatite

\begin{tabular}{|l|l|l|l|l|}
\hline & apatite/LN5 & apatite/LN I0 & apatite/LN20 & apatite/LN40 \\
\hline Coprecipitated amount of LN $(\mu \mathrm{g})$ & $1.43 \pm 0.55$ & $3.96 \pm 0.88$ & $4.14 \pm 0.75$ & $5.88 \pm 1.23$ \\
\hline
\end{tabular}

Note: Values are represented as mean $\pm \operatorname{SD}(n=3)$.

Abbreviation: LN, laminin.

XPS data confirmed the results of quantitative assay based on the mBCA assay.

The retention of the immobilized protein is critical for practical application. We investigated the release kinetics and retention of coprecipitated FITC-LN at a biological environment. Titanium substrates coated with apatite/FITC-LN20 were immersed in PBS solution for 28 days. The release kinetics of FITC-LN from biomimetic apatite is depicted in
Figure 4A. The FITC-LN was released stably and constantly After 6 and 12 hours, $1.61 \% \pm 0.20 \%$ and $1.73 \% \pm 0.18 \%$ of coprecipitated FITC-LNs were released into PBS solution, respectively. Even after 28 days, only approximately $20.72 \%$ of FITC-LN immobilized within biomimetic apatite was released into the solution. The fluorescent images in Figure 4B shows the change in cross-section profiles, which were acquired by stacking a series of images obtained through
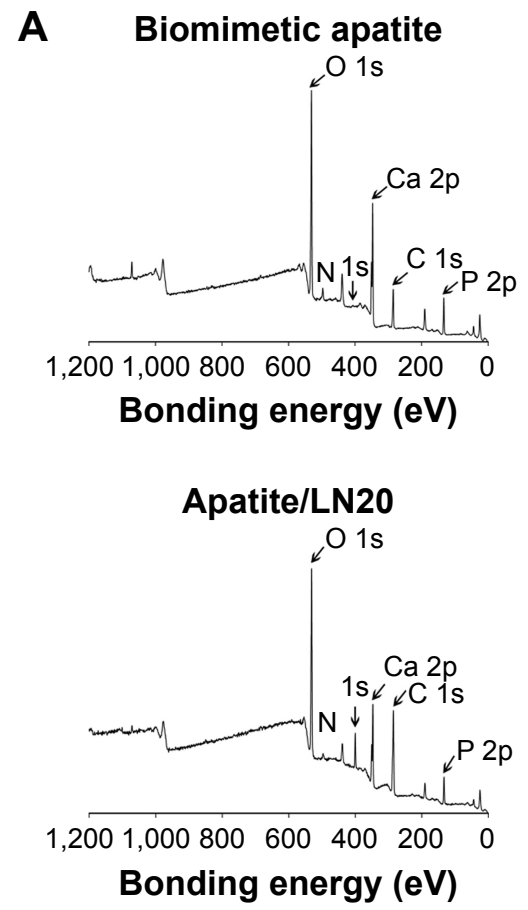

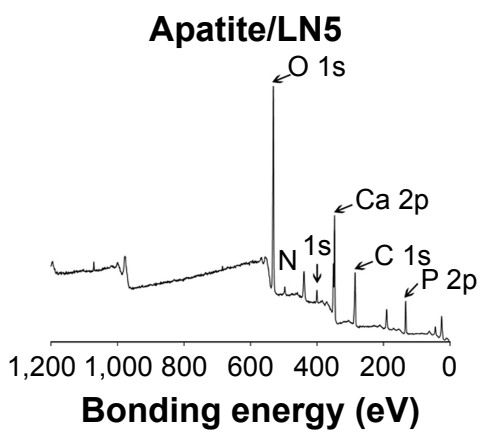

Apatite/LN40

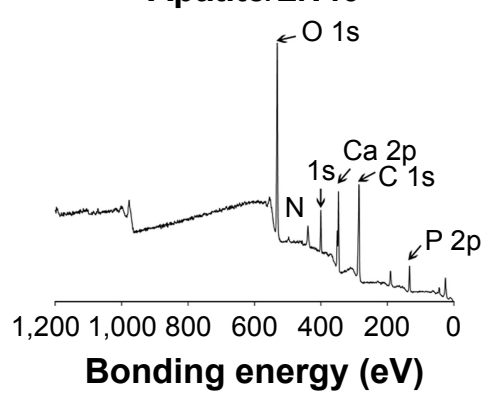

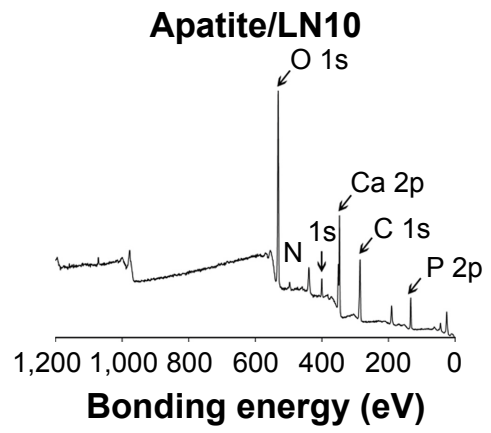

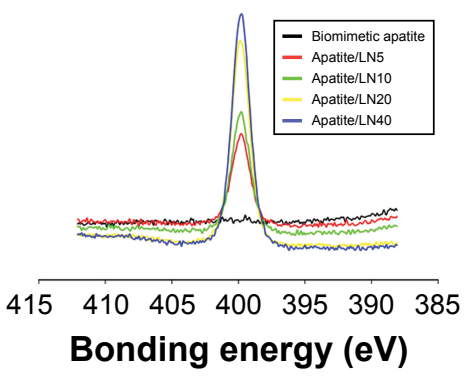

B

\begin{tabular}{llllll}
\hline & Ca 2p (at\%) & P 2p (at\%) & C 1s (at\%) & O 1s (at\%) & N 1s (at\%) \\
\hline $\begin{array}{l}\text { Biomimetic } \\
\text { apatite }\end{array}$ & 17.68 & 14.06 & 18.61 & $49 . .08$ & 0.57 \\
Apatite/LN5 & 14.73 & 11.76 & 27.01 & 43.37 & 3.13 \\
Apatite/LN10 & 13.41 & 10.88 & 31.24 & 40.16 & 4.31 \\
Apatite/LN20 & 9.74 & 8.26 & 40.61 & 33.89 & 7.5 \\
Apatite/LN40 & 8.54 & 7.27 & 44.11 & 31.63 & 8.45 \\
\hline
\end{tabular}

Figure 3 XPS analysis of representative samples.

Notes: (A) XPS peaks of biomimetic apatite and apatite with coprecipitated LN (apatite/LN5, apatite/LN I0, apatite/LN20, and apatite/LN40). Magnified graph shows nitrogen (N) peaks in the biomimetic apatite and apatite/LN in the bottom right panel. (B) Quantification of atomic compositions on the surfaces of representative samples. Abbreviations: LN, laminin; XPS, X-ray photoelectron spectroscopy. 


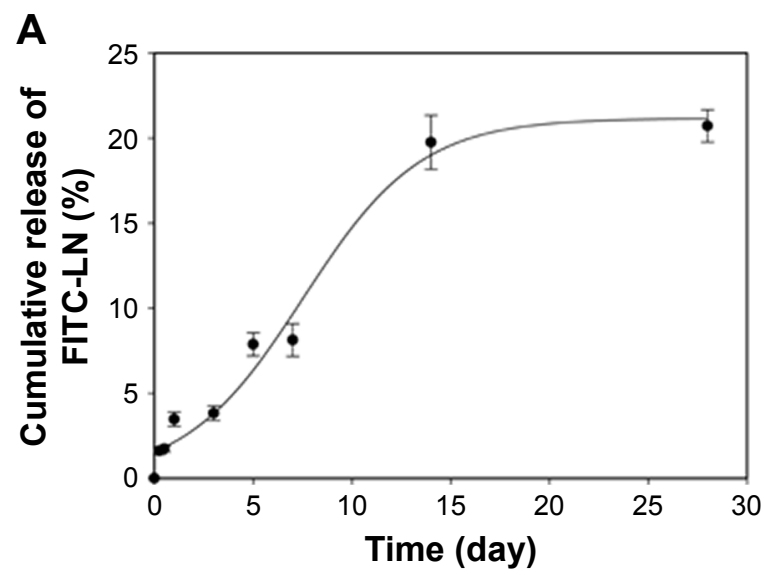

B

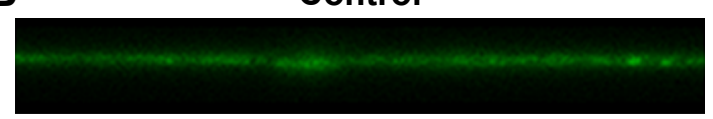

After 28 days in PBS

Figure 4 (A) In vitro release of apatite/FITC-LN20 in PBS over 28-day time period. Values are represented as mean $\pm S D(n=3)$. (B) Side depth profiles obtained by stacking each series of confocal images through the thickness of apatite/FITC-LN20 after immersing in PBS solution for 28 days and control sample.

Abbreviations: FITC-LN, fluorescein isothiocyanate-conjugated LN; LN, laminin.

the thickness of apatite/FITC-LN20. Consistent and even fluorescence occurred over control sample and apatite/FITCLN20 after immersing in PBS solution for 28 days. The width of fluorescence decreased by $28.45 \%$ after 28 -day immersion, which is accordant with the quantitative result.

\section{Initial cell adhesion}

NSCs were seeded on biomimetic apatite and apatite with coprecipitated LN (apatite/LN5, apatite/LN10, apatite/ LN20, and apatite/LN40) in growth medium for a period of 12 hours, and the results of cell adhesion are summarized in Figure 5. A very small extent NSCs attached onto surfaces of negative control and biomimetic apatite. For apatite/LN5, the extent of adhesion was slightly higher with no statistical significance than biomimetic apatite. For apatite/LN10, apatite/LN20, and apatite/LN40, significantly higher cell adhesion was observed, but still lower than positive control. Notably, the NSC adhesion increased with increasing amount of coprecipitated LN, even though the extents of NSC adhesion between apatite/LN20 and apatite/LN40 were comparable $(P>0.05)$. So we chose apatite/LN20 for the further cell experiments.
The detailed NSCs adhesion was further observed on biomimetic apatite and apatite/LN20 for 12 hours by SEM (Figure 5B). The NSCs could spread well on both biomimetic apatite and apatite/LN20. However, cells adhered on apatite/LN20 exhibited more processes (shown as red circle in Figure 5B) than that on biomimetic apatite.

\section{Short- and long-term NSC proliferation}

To determine whether LN coprecipitated apatite can support short- and long-term NSC culture, the proliferation of NSCs cultivated on biomimetic apatite and apatite/LN20 in growth medium over 10 days was investigated. At the predetermined time point, the viability of NSC cultivated on biomimetic apatite and apatite/LN20 was evaluated by CCK8 (Figure 6).

After 3- and 5-day cultivation, NSCs proliferated with significantly higher cell numbers on positive control compared to biomimetic apatite, apatite/LN20, and negative control. Around 50\% more NSCs were found on the surfaces of apatite/LN20 than on biomimetic apatite and negative control. The viabilities of attached NSCs continued to increase on day 7 and day 10 (except negative control), which indicated that most NSCs remained viable and kept proliferating. The level of proliferation revealed by apatite/LN20 caught up and became comparable to that of positive control. The biomimetic apatite samples even showed significant increase in NSC proliferation compared to negative control.

\section{NSC cytotoxicity}

We further investigated the NSC cytotoxicity of biomimetic apatite and apatite/LN20 by means of CCK8 and the live/ dead viability/cytotoxicity kit. As shown in Figure 7A, CCK8 assay of NSC exposed to extract mediums revealed that cell viability compared with negative control was $91.05 \%$ and $92.16 \%$ for biomimetic apatite and apatite/LN20, respectively. This was higher than the threshold for cytotoxicity, which has been set at $70 \%$ according to the ISO standard (ISO: 10993-5:2009[9]). ${ }^{34}$

The live/dead viability/cytotoxicity kit provides a twocolor fluorescence in cell viability test. ${ }^{35}$ Live cells with intracellular esterase activity could converse the non-fluorescent cell-permeant Calcein AM to fluorescent calcein, which show green fluorescence. ${ }^{36}$ On the other hand, EthD-1 enters dead cells with damaged membranes and undergoes enhancement of fluorescence with binding to nucleic acids, thereby producing red fluorescence in dead cells. ${ }^{37}$ Figure $7 \mathrm{~B}$ shows live (green)/dead (red) stain of NSC in contact with extract 


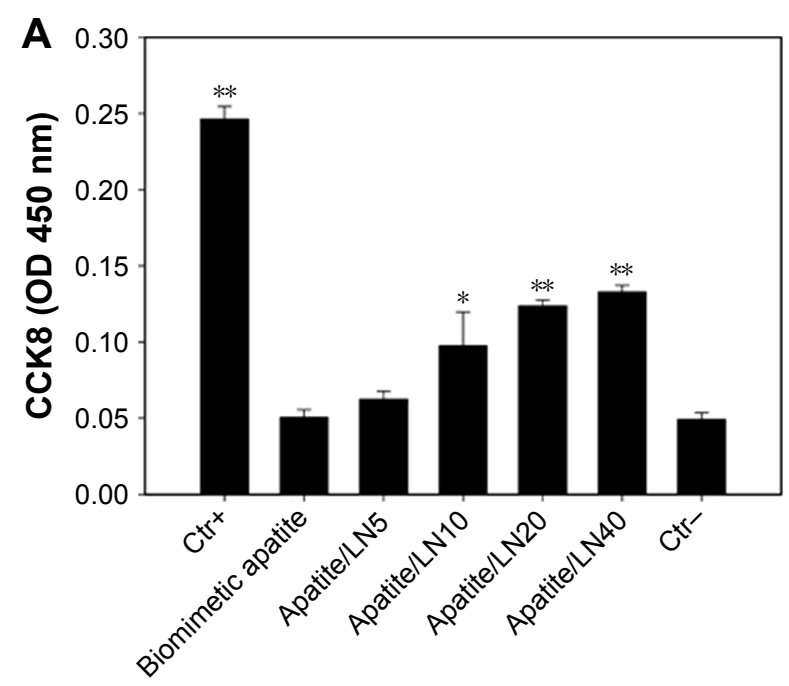

B
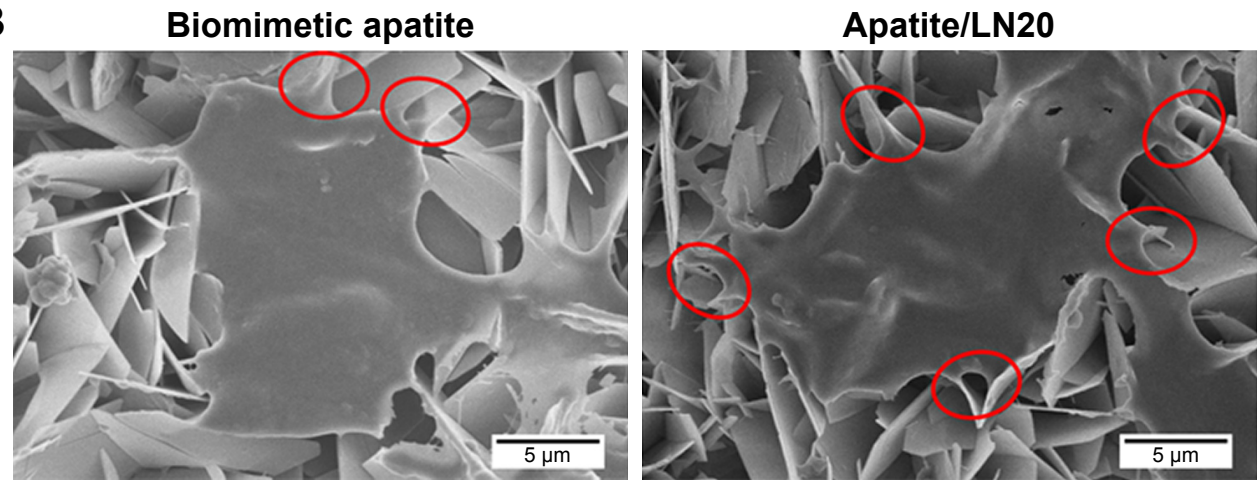

Figure 5 NSCs adhesion on surfaces of biomimetic apatite and apatite with coprecipitated LN (apatite/LN5, apatite/LN I0, apatite/LN20, and apatite/LN40) samples in growth medium after 12-hour culture.

Notes: (A) Attached cells were assayed by CCK8. Values are represented as mean $\pm S D(n=3)$. Statistical significance relative to the group of biomimetic apatite: $* P<0.05$; $* * P<0.01$. (B) SEM images of NSCs attached on biomimetic apatite and apatite/LN20. The red circle pointed the processes from the cell body. Scale bar is $5 \mu m$ in length. Abbreviations: CCK8, Cell Counting Kit-8; Ctr+, positive control; Ctr-, negative control; LN, laminin; NSC, neural stem cell; SEM, scanning electron microscopy.

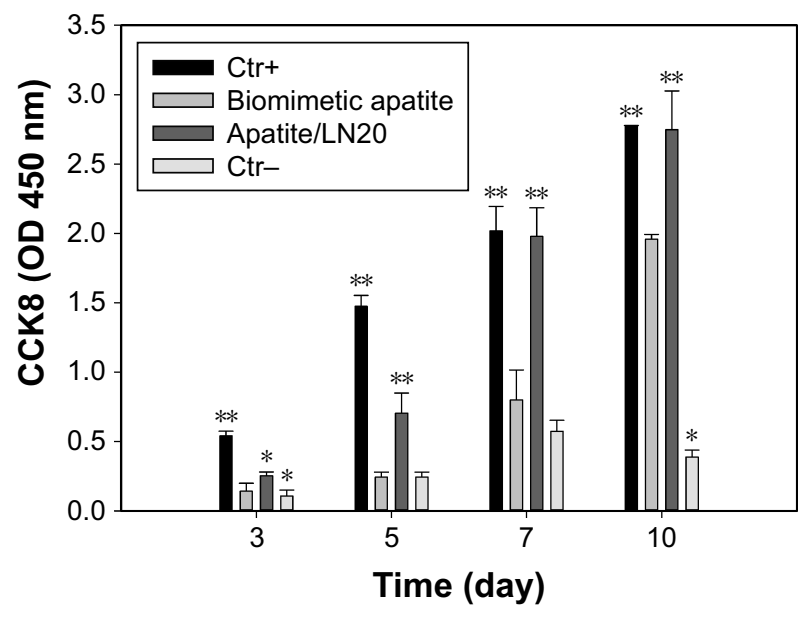

Figure 6 NSCs proliferation on surfaces of biomimetic apatite and apatite/LN20 samples in growth medium for 3, 5, 7 and 10 days.

Notes: Cells were assayed by CCK8. Values are represented as mean \pm SD $(n=3)$. Statistical significance relative to the group of biomimetic apatite: $* P<0.05$; $* * p<0.01$.

Abbreviations: CCK8, Cell Counting Kit-8; Ctr+, positive control; Ctr-, negative control; LN, laminin; NSC, neural stem cell. mediums of biomimetic apatite and apatite/LN20 for 48-hour incubation. For biomimetic apatite and apatite/LN20, green fluorescence emission signal was dominated and comparable with negative control, indicating that our substrates supported NSC adhesion and proliferation without cytotoxicity.

\section{Discussion}

NSCs have emerged as an attractive cell source for cell therapies and tissue engineering applications that treat traumatic injury and degenerative disease of nervous system. ${ }^{38}$ However, the number of living transplanted NSCs decreased rapidly due to the lack of physicochemical cues and/or biological signals in surrounded microenvironment. ${ }^{39}$ Therefore, functionalizing substrates with biological molecules, such as polymer, peptide, or proteins, can provide artificial microenvironments to enhance NSC adhesion and growth by promoting cell-substrate interactions ${ }^{40}$ Several 


\section{A}
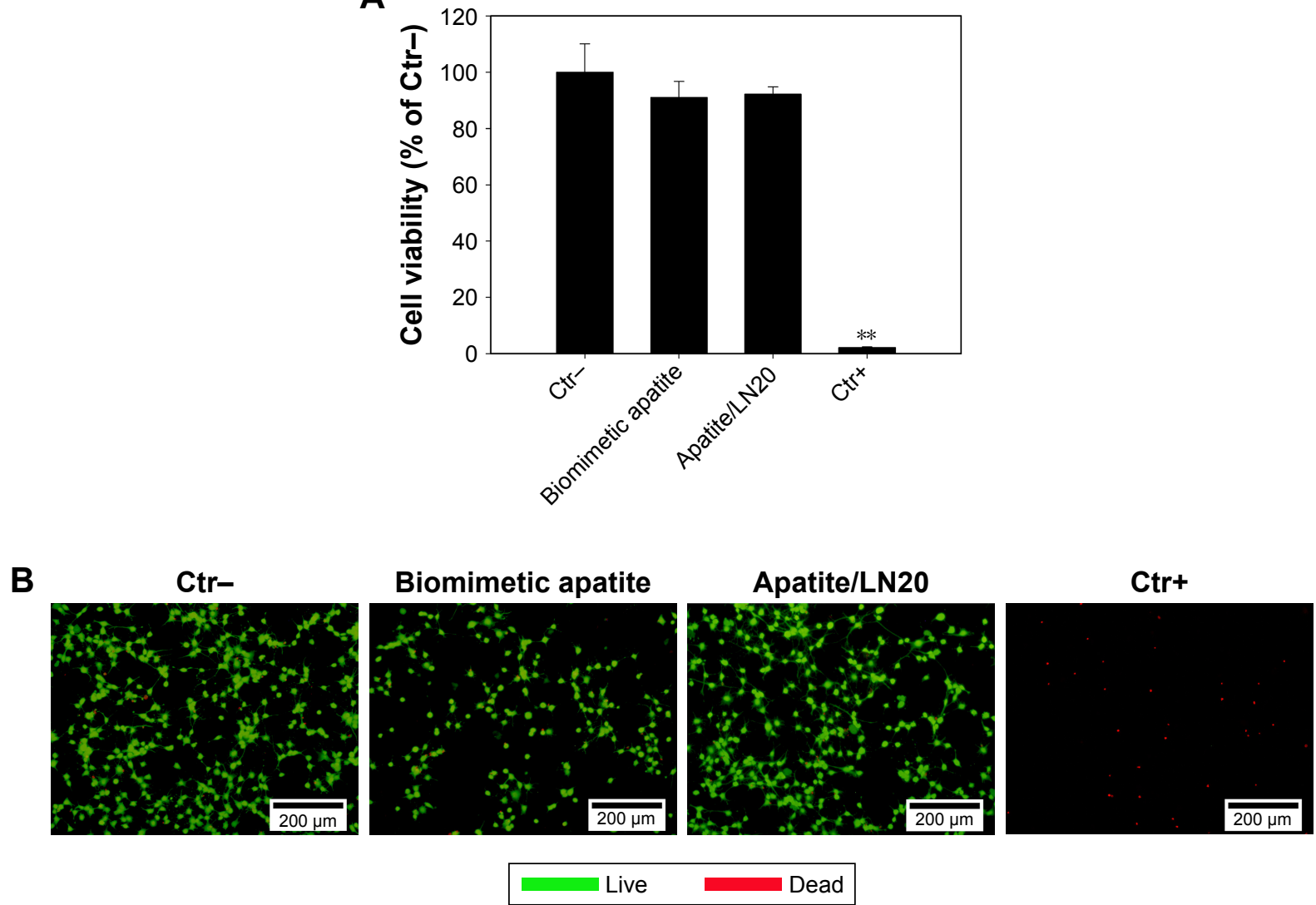

Figure 7 NSCs were cultured in indirect contact with biomimetic apatite and apatite/LN20 for 48-hour incubation to evaluate the cytotoxicity.

Notes: $(\mathbf{A})$ Cell viability was quantitatively analyzed by CCK8. Values are represented as mean \pm SD $(n=3)$. Statistical significance relative to the group of negative control: $* * P<0.0$ I. (B) Cytotoxicity was qualitatively observed by the live/dead viability/cytotoxicity kit (green color: live cells, red color: dead cells). Scale bar is $200 \mu \mathrm{m}$ in length. Abbreviations: CCK8, Cell Counting Kit-8; Ctr+, positive control; Ctr-, negative control; LN, laminin; NSC, neural stem cell.

studies demonstrate that substrates modified with ECM proteins or derived peptides by physical adsorption or covalent bonding could support adhesion and proliferation of NSC. However, these approaches remain challenging because of rapid diffusion in fluids ${ }^{14}$ or complicated procedures, ${ }^{15}$ respectively.

Biomimetic apatite has attracted much interest for biomedical applications due to its instinct properties such as excellent biocompatibility, non-toxicity, and high affinity to many biological molecules. ${ }^{41}$ Previous studies showed that coprecipitation of biological molecules with biomimetic apatite is an efficient and simple method to bio-functionalize diverse substrates. ${ }^{42-44}$ However, it has not been explored for NSC behaviors yet.

$\mathrm{LN}$, one of the ECM glycoproteins, is important for neural development by promoting cell adhesion, proliferation, migration, and neurite outgrowth. ${ }^{45}$ Herein, we immobilized LN within biomimetic apatite by the coprecipitation approach to modulate NSC adhesion and proliferation. It has been confirmed that the degradation of biomimetic apatite in neutral solution, ${ }^{46}$ together with diffusion of molecules from biomimetic apatite, ${ }^{28}$ can successfully control the slow release of LN for long term (28 days; Figure 4). This indicated that coprecipitation of biological molecules within biomimetic apatite may provide spatial control of NSC behaviors through a stable and constant dosage of immobilized molecules, which is rare to be achieved through the physical adsorption approach. $^{47}$

The initial attachment of NSCs is a crucial early step in the proliferation and migration of NSCs and consequent tissue response in vivo. ${ }^{48}$ The biomimetic apatite displaying $\mathrm{LN}$ at various amounts were assayed for NSC adhesion. The achieved amounts of coprecipitated LN (except apatite/LN5) were high enough to improve NSC adhesion, and it was dependent on LN coprecipitated amount (Figure 5A).

The promotion of NSCs proliferation will be critical to the clinical application of cell therapy or tissue engineering strategy. ${ }^{49}$ For the short-term (day 3 and 5) cultivation, in which cell-cell interaction is still weak and cell-surface interaction is favored, ${ }^{50}$ the number of cells increased significantly relative to the initial cell attachment. At this early stage, the proliferation level of positive control was much higher than 
that of biomimetic apatite and apatite/LN20. In long-term (day 7 and 10) NSC proliferation, the quantitative results (CCK8 data) indicated that apatite/LN20 could improve NSC proliferation to a similar extent as positive control, implying that cell-cell interaction gradually dominated with cell proliferating.

In the immunofluorescence images as show in Figure 8, the NSCs on all surfaces were immune positive for nestin, which indicated that NSCs were still undergoing proliferation in an immature state. But there were distinguishing differences in cell morphology on each sample. As cells did not attach strongly to negative control, very few proliferated cells were observed on both day 7 and 10. On the surface of biomimetic apatite only, few cells on day 7 and more proliferated cells but aggregated on day 10, similar to the behaviors of NSC growth in suspension, were observed, indicating poor adhesion to biomimetic apatite. On day 7 , NSCs adhered well as single cells on both apatite/LN20 and LN-coated TCP (positive control) to form a uniform monolayer. On day 10, the amount of physically adsorbed LN on TCP decreased to an insufficient level for stable cell adhesion, by regularly changing culture medium every 3 days and washing sample thoroughly for fluorescent staining. The bare region was partially exposed on positive control due to the detachment or retraction of NSCs, which was also observed by Ananthanarayanan et al. ${ }^{51}$ The majority of proliferated cells on apatite/LN20 remained and adhered firmly, as the sustained release of $\mathrm{LN}$ from biomimetic apatite provided stable cell-surface interaction for cell proliferation in a prolonged cultivation.

For biomedical applications involving NSCs, surface modification that provides stable cell surface adhesion and promotes cell proliferation is crucial. ${ }^{52}$ Covalent chemical conjugation has been applied to immobilize biological molecules, such as collagen type I, ${ }^{53}$ TATVHL peptide, ${ }^{54}$ and nerve growth factor, ${ }^{15}$ onto supported substrates to facilitate NSC adhesion and improve proliferation. However, these methods require complicated and multistep chemical procedures, which result in batch-to-batch variation, molecule denaturation, and substrate toxicity. ${ }^{55}$ The present study illustrates that the biomimetic apatite with coprecipitated $\mathrm{LN}$ is neither cytotoxic nor has negative influences on NSC adhesion and proliferation. Therefore, loading biological molecules within biomimetic apatite through the simple and reproducible coprecipitation approach is promising for neural-related applications.

\section{Conclusion}

Biomimetic apatite was formed as a carrier to functionalize substrates with LN through the coprecipitation approach. The flake size of apatite slightly increased with the amount of coprecipitated LN. Apatite/LN20 showed the optimal NSC adhesion and well-spread cell morphology. The apatite/LN20 also supported NSC proliferation without causing any NSC cytotoxicity. As a result of sustained LN release form apatite/ LN20, a more stable monolayer of NSCs was observed than
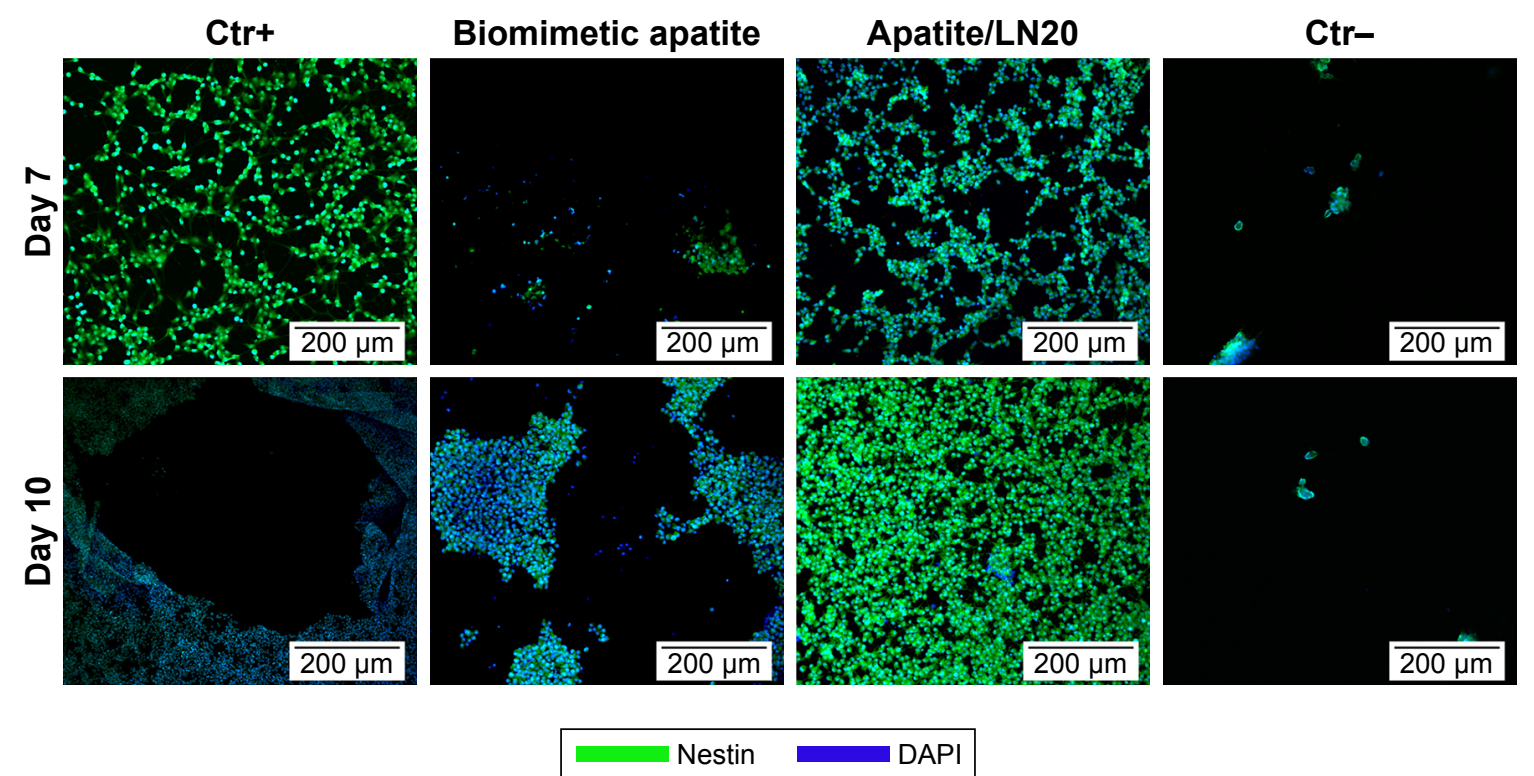

Figure 8 Immunofluorescence images of nestin (a NSC marker, green) and DAPI (blue) staining of NSCs proliferation on surfaces of biomimetic apatite and apatite/LN20 samples in growth medium for 7 and 10 days. Scale bar is $200 \mu \mathrm{m}$ in length.

Abbreviations: Ctr+, positive control; Ctr-, negative control; LN, laminin; NSC, neural stem cell. 
LN-coated TCP. Therefore, surface modification of neural scaffolds or implantable devices by coprecipitating biological signals within biomimetic apatite is promising for neuralrelated applications.

\section{Acknowledgments}

This research was supported partly by National Natural Science Foundation of China (51502265, 51572242), partly by Zhejiang Provincial Natural Science Foundation of China (LQ16E020006), and partly by Basic Science Research Program through the National Research Foundation of Korea (NRF) funded by the Ministry of Education, Korea (2015R1D1A1A09058875).

\section{Disclosure}

The authors report no conflicts of interest in this work.

\section{References}

1. Grabel L. Developmental origin of neural stem cells: the glial cell that could. Stem Cell Rev. 2012;8(2):577-585.

2. Hsieh J, Schneider JW. Neuroscience. Neural stem cells, excited. Science. 2013;339(6127):1534-1535.

3. Rockenstein E, Desplats P, Ubhi K, et al. Neuropeptide treatment with cerebrolysin enhances the survival of grafted neural stem cell in an $\alpha$-synuclein transgenic model of Parkinson's disease. J Exp Neurosci. 2015;9(Suppl 2):131-140.

4. Ager RR, Davis JL, Agazaryan A, et al. Human neural stem cells improve cognition and promote synaptic growth in two complementary transgenic models of Alzheimer's disease and neuronal loss. Hippocampus. 2015;25(7):813-826.

5. Péron S, Berninger B. Imported stem cells strike against stroke. Cell Stem Cell. 2015;17(5):501-502.

6. Ernst C. Proliferation and differentiation deficits are a major convergence point for neurodevelopmental disorders. Trends Neurosci. 2016;39(5):290-299.

7. Wilkinson AE, Kobelt LJ, Leipzig ND. Immobilized ECM molecules and the effects of concentration and surface type on the control of NSC differentiation. J Biomed Mater Res A. 2014;102(10):3419-3428.

8. Su WT, Liao YF, Lin CY, Li LT. Micropillar substrate influences the cellular attachment and laminin expression. J Biomed Mater Res A. 2010;93(4):1463-1469.

9. Neal RA, Tholpady SS, Foley PL, Swami N, Ogle RC, Botchwey EA. Alignment and composition of laminin-polycaprolactone nanofiber blends enhance peripheral nerve regeneration. J Biomed Mater Res A. 2012;100(2):406-423.

10. Costa FM, Maia SR, Gomes PA, Martins MC. Dhvar5 antimicrobial peptide (AMP) chemoselective covalent immobilization results on higher antiadherence effect than simple physical adsorption. Biomaterials. 2015;52(1):531-538.

11. Holt AP, Bocharova V, Cheng S, et al. Controlling interfacial dynamics: Covalent bonding versus physical adsorption in polymer nanocomposites. ACS Nano. 2016;10(7):6843-6852.

12. Yu X, Walsh J, Wei M. Covalent immobilization of collagen on titanium through polydopamine coating to improve cellular performances of MC3T3-E1 cells. RSC Adv. 2013;4(14):7185-7192.

13. Wang X, Liu A, Xing Y, et al. Three-dimensional graphene biointerface with extremely high sensitivity to single cancer cell monitoring. Biosens Bioelectron. 2018;105:22-28.

14. Gagner JE, Qian X, Lopez MM, Dordick JS, Siegel RW. Effect of gold nanoparticle structure on the conformation and function of adsorbed proteins. Biomaterials. 2012;33(33):8503-8516.
15. Yang K, Lee JS, Kim J, et al. Polydopamine-mediated surface modification of scaffold materials for human neural stem cell engineering. Biomaterials. 2012;33(29):6952-6964.

16. Jayasuriya AC, Shah C, Ebraheim NA, Jayatissa AH. Acceleration of biomimetic mineralization to apply in bone regeneration. Biomed Mater. 2008;3(1):015003.

17. Chatelain G, Bourgeois D, Ravaux J, Averseng O, Vidaud C, Meyer D. Incorporation of uranium into a biomimetic apatite: physicochemical and biological aspects. J Biol Inorg Chem. 2015;20(3):497-507.

18. Cazalbou S, Bertrand G, Drouet C. Tetracycline-loaded biomimetic apatite: an adsorption study. J Phys Chem B. 2015;119(7):3014-3024.

19. Chen C, Zhang S-M, Lee I-S. Immobilizing bioactive molecules onto titanium implants to improve osseointegration. Surf Coat Technol. 2013;228(8):S312-S317.

20. Choimet M, Tourrette A, Drouet C. Adsorption of nucleotides on biomimetic apatite: The case of cytidine $5^{\prime}$ monophosphate (CMP). J Colloid Interface Sci. 2015;456:132-137.

21. Hammami K, Feki HE, Marsan O, Drouet C. Adsorption of nucleotides on biomimetic apatite: The case of adenosine $5^{\prime}$ monophosphate (AMP). Appl Surf Sci. 2015;353:165-172.

22. Chen C, Lee IS, Zhang SM, Yang HC. Biomimetic apatite formation on calcium phosphate-coated titanium in Dulbecco's phosphate-buffered saline solution containing $\mathrm{CaCl}_{2}$ with and without fibronectin. Acta Biomater. 2010;6(6):2274-2281.

23. Sasaki K, Oyane A, Hyodo K, et al. Preparation and biological evaluation of a fibroblast growth factor-2-apatite composite layer on polymeric material. Biomed Mater. 2010;5(6):065008.

24. Lin X, Li X, Fan H, Wen X, Lu J, Zhang X. In situ synthesis of bonelike apatite/collagen nano-composite at low temperature. Mater Lett. 2004;58(27-28):3569-3572.

25. Liu Y, Layrolle P, de Bruijn J, van Blitterswijk C, de Groot K. Biomimetic coprecipitation of calcium phosphate and bovine serum albumin on titanium alloy. $J$ Biomed Mater Res. 2001;57(3):327-335.

26. Luong LN, Hong SI, Patel RJ, Outslay ME, Kohn DH. Spatial control of protein within biomimetically nucleated mineral. Biomaterials. 2006;27(7):1175-1186.

27. Chen C, Li H, Kong X, Zhang SM, Lee IS. Immobilizing osteogenic growth peptide with and without fibronectin on a titanium surface: effects of loading methods on mesenchymal stem cell differentiation. Int J Nanomedicine. 2015;10:283-295.

28. Chen C, Yao C, Yang J, et al. Biomimetic apatite formed on cobaltchromium alloy: A polymer-free carrier for drug eluting stent. Colloids Surf B Biointerfaces. 2017;151:156-164.

29. Yamaguchi I, Itoh S, Suzuki M, Osaka A, Tanaka J. The chitosan prepared from crab tendons: II. The chitosan/apatite composites and their application to nerve regeneration. Biomaterials. 2003;24(19):3285-3292.

30. Wei YT, Tian WM, Yu X, et al. Hyaluronic acid hydrogels with IKVAV peptides for tissue repair and axonal regeneration in an injured rat brain. Biomed Mater. 2007;2(3):S142-S146.

31. Mie M, Sasaki S, Kobatake E. Construction of a bFGF-tethered multifunctional extracellular matrix protein through coiled-coil structures for neurite outgrowth induction. Biomed Mater. 2014;9(1):015004.

32. Maurer MH, Thomas C, Bürgers HF, Kuschinsky W. Transplantation of adult neural progenitor cells transfected with Vascular Endothelial Growth Factor rescues grafted cells in the rat brain. Int J Biol Sci. 2008; $4(1): 1-7$.

33. Vandrovcova $M$, Vacik J, Svorcik V, et al. Fullerene $\mathrm{C}_{60}$ and hybrid $\mathrm{C}_{60} /$ Ti films as substrates for adhesion and growth of bone cells. Physica Status Solidi. 2008;205(9):2252-2261.

34. van Essen TH, van Zijl L, Possemiers T, et al. Biocompatibility of a fish scale-derived artificial cornea: Cytotoxicity, cellular adhesion and phenotype, and in vivo immunogenicity. Biomaterials. 2016;81:36-45.

35. Choi JY, Lee SH, Na HB, An K, Hyeon T, Seo TS. In vitro cytotoxicity screening of water-dispersible metal oxide nanoparticles in human cell lines. Bioprocess Biosyst Eng. 2010;33(1):21-30.

36. Li M, Xu C, Wu L, Wu P, Hou X. Dually enriched Cu:CdS@ZnS QDs with both polyvinylpyrrolidone twisting and $\mathrm{SiO}_{2}$ loading for improved cell imaging. Chem Commun. 2015;51(17):3552-3555. 
37. Ciofani G, Ricotti L, Danti S, et al. Investigation of interactions between poly-L-lysine-coated boron nitride nanotubes and $\mathrm{C} 2 \mathrm{C} 12$ cells: up-take, cytocompatibility, and differentiation. Int J Nanomedicine. 2010; 5(1):285-298.

38. Chen HI, Bakshi A, Royo NC, Magge SN, Watson DJ. Neural stem cells as biological minipumps: a faster route to cell therapy for the CNS? Curr Stem Cell Res Ther. 2007;2(1):13-22.

39. Martínez-Ramos C, Lainez S, Sancho F, et al. Differentiation of postnatal neural stem cells into glia and functional neurons on laminin-coated polymeric substrates. Tissue Eng Part A. 2008;14(8):1365-1375.

40. Park HJ, Yang K, Kim MJ, et al. Bio-inspired oligovitronectin-grafted surface for enhanced self-renewal and long-term maintenance of human pluripotent stem cells under feeder-free conditions. Biomaterials. 2015;50(1):127-139.

41. Liu F, Meng Q, Chen C, Cui F, Liu Y, Lee I-S. Loading collagen and hydroxycholesterol within biomimetic mineral onto titanium: Synergistically promoting osteogenic expression of mesenchymal stem cells. J Biomater Tissue Eng. 2015;5(2):169-176.

42. Chen C, Qiu ZY, Zhang SM, Lee IS. Biomimetic fibronectin/mineral and osteogenic growth peptide/mineral composites synthesized on calcium phosphate thin films. Chem Commun. 2011;47(39):11056-11058.

43. Yokoyama Y, Oyane A, Ito A. Biomimetic coating of an apatite layer on poly(L-lactic acid); improvement of adhesive strength of the coating. J Mater Sci Mater Med. 2007;18(9):1727-1734.

44. Chen Y, Mak AF, Wang M, Li J. Composite coating of bonelike apatite particles and collagen fibers on poly L-lactic acid formed through an accelerated biomimetic coprecipitation process. J Biomed Mater Res B Appl Biomater. 2006;77(2):315-322.

45. Koh HS, Yong T, Chan CK, Ramakrishna S. Enhancement of neurite outgrowth using nano-structured scaffolds coupled with laminin. Biomaterials. 2008;29(26):3574-3582.

46. Barrère F, van der Valk CM, Dalmeijer RA, van Blitterswijk CA, de Groot K, Layrolle P. In vitro and in vivo degradation of biomimetic octacalcium phosphate and carbonate apatite coatings on titanium implants. J Biomed Mater Res A. 2003;64(2):378-387.
47. Dong M, Wu Z, Lu M, Wang Z, Li Z. Combining the physical adsorption approach and the covalent attachment method to prepare a bifunctional bioreactor. Int J Mol Sci. 2012;13(9):11443-11454.

48. Wang TY, Forsythe JS, Parish CL, Nisbet DR. Biofunctionalisation of polymeric scaffolds for neural tissue engineering. J Biomater Appl. 2012;27(4):369-390.

49. Christopherson GT, Song H, Mao HQ. The influence of fiber diameter of electrospun substrates on neural stem cell differentiation and proliferation. Biomaterials. 2009;30(4):556-564.

50. Xie H, Li J, Li L, Dong Y, Chen GQ, Chen KC. Enhanced proliferation and differentiation of neural stem cells grown on PHA films coated with recombinant fusion proteins. Acta Biomater. 2013;9(8):7845-7854.

51. Ananthanarayanan B, Little L, Schaffer DV, Healy KE, Tirrell M. Neural stem cell adhesion and proliferation on phospholipid bilayers functionalized with RGD peptides. Biomaterials. 2010;31(33):8706-8715.

52. Guo R, Zhang S, Xiao M, et al. Accelerating bioelectric functional development of neural stem cells by graphene coupling: Implications for neural interfacing with conductive materials. Biomaterials. 2016; 106:193-204.

53. Chang MC, Tanaka J. XPS study for the microstructure development of hydroxyapatite-collagen nanocomposites cross-linked using glutaraldehyde. Biomaterials. 2002;23(18):3879-3885.

54. Kuo YC, Chung CY. TATVHL peptide-grafted alginate/poly $(\gamma$-glutamic acid) scaffolds with inverted colloidal crystal topology for neuronal differentiation of iPS cells. Biomaterials. 2012;33(35):8955-8966.

55. Coad BR, Jasieniak M, Griesser SS, Griesser HJ. Controlled covalent surface immobilisation of proteins and peptides using plasma methods. Surf Coat Technol. 2013;233(16):169-177.
International Journal of Nanomedicine

\section{Publish your work in this journal}

The International Journal of Nanomedicine is an international, peerreviewed journal focusing on the application of nanotechnology in diagnostics, therapeutics, and drug delivery systems throughout the biomedical field. This journal is indexed on PubMed Central, MedLine, CAS, SciSearch $\AA$, Current Contents $₫ /$ Clinical Medicine,

\section{Dovepress}

Journal Citation Reports/Science Edition, EMBase, Scopus and the Elsevier Bibliographic databases. The manuscript management system is completely online and includes a very quick and fair peer-review system, which is all easy to use. Visit http://www.dovepress.com/ testimonials.php to read real quotes from published authors. 